\title{
Multicriteria Spatial Decision Support System for Soil Fertility Assessment in Agriculture
}

\author{
Neelam Agrawal \\ Department of Computer \\ Applications, National Institute of \\ Technology Raipur, \\ Raipur, India
}

\author{
Kesari Verma \\ Department of Computer \\ Applications, National Institute of \\ Technology Raipur, \\ Raipur, India
}

\author{
Tarun Kumar \\ Department of Soil and Water \\ Engineering, Krishi Vigyan Kendra \\ (KVK) Saraiya, \\ Muzaffarpur, India
}

\begin{abstract}
The main goal of smart agriculture is balanced fertilization that is guided by the conflicting objectives of sustainability and productivity. The Geographical information system (GIS) is an effective way to manage, store, analyze, retrieve, modify, and display spatial information. However, it lacks in supporting spatial decisions through analytical approaches. The integrated approach of GIS and Multi-Criteria Decision Analysis (MCDA) models allow us to overcome such tradeoffs. This study aims to develop a web-GIS-based, MultiCriteria Spatial Decision Support System (MCSDSS) to support fertility assessment of the farmland. The proposed framework is useful in identifying the farmland's optimum fertilizer requirements, which will ultimately increase farm profitability, productivity, and sustainability with reduced environmental pollution. To achieve the objective multiple soil attributes with varying significance and nature are evaluated using the MCDA models of Weighted Sum Model (WSM), Weighted Product Model (WPM), and Weighted Aggregated Sum Product Assessment (WASPAS). The proposed multi-criteria spatial decision support system suggests soil's fertilizer requirement into the categories of low, moderate, and high levels. The results reveal that the WPM MCDA model outperformed among all with an accuracy of $82.9 \%$.
\end{abstract}

\section{General Terms}

Decision Support System

\section{Keywords}

Fertilizer Recommendations, Multi-Criteria Decision Analysis, Web-GIS, Decision Support System, Weighted Aggregated Sum Product Assessment, Weighted Sum Model, Weighted Product Model

\section{INTRODUCTION}

Agriculture is a major occupation and plays an important role in the Indian economy as it employs a large workforce and contributes significantly to the national income. It can also be considered as a way to enhance the quality of life in rural areas where a majority of people are dependent on agriculture. Also, to meet the ever-growing nutritional demand for supporting the growing population, agriculture productivity has to grow. Therefore, technological advancement, proper management, and planning are needed in the agriculture sector to achieve improved productivity and sustainability for the progression of the nation [1].

During the continuous and rotational agricultural production process, nutrients are taken from the soil through farming produce. Therefore, nutrient replacement or fertilizer application is an inevitable process for preserving soil fertility and to achieve optimum productivity. The applicability of fertilizer dosage depends upon the soil nutrients status. Unbalanced or improper use of chemical fertilizer can lead to decreased farmland productivity and increased environmental pollution. Although chemical fertilizers are vital for boosting soil fertility, but long-term use of improper dosage of it can result in degradation of the soil's quality and other environmental consequences [2] [3] [4]. Balanced measurement of required fertilizer dosage is the most vital input for keeping soil fertility and productivity with reduced environmental pollution and resources required [5] [6]. Thus, for developing a productive and sustainable agro-ecosystem, the soil fertility assessment process is an essential practice [7]. This study aims to propose a web-based, multi-criteria spatial decision support system for assessing soil fertility to assist the farmers in the prediction of balanced fertilizer dosage.

Current progressions in the field of Information Technology domain are required to be adopted into the agriculture sector also. With the help of Geographic Information Systems (GIS), it is convenient to capture, store, retrieve, manage, and visualize multiple spatial information, for example, soil's property, crop type, climatic information, etc., concurrently and accurately. However, it lacks in supporting spatial decisions through analytical abilities. Multi-Criteria Decision Analysis (MCDA) models can facilitate the decision-making process in a situation of multiple heterogeneous criteria of differing importance. The spatial variability of the soil gives rise to employ MCDA models for efficient fertilizer usage. The combined approach of GIS and MCDA models [8] has provided us the opportunity to develop web-GIS-based MultiCriteria Spatial Decision Support Systems (MCSDSS) for the prediction of optimum dosage of farm's fertilizer requirements using specific soil attributes. The decision-making process comprises the inclusion of spatial soil data and the weightage of selected soil attributes, computation of preference scores based on decision rules, and finally, providing the decisions about required fertilizer dosage to the end-user based on the preference scores [9].

There are many studies that are proposed in the literature regarding the issue of fertilizer assessment. Lavanya et al. [10] presented an Internet of Things (IoT) based system for monitoring and intimating soil nutrient levels in the farm field. A fuzzy logic-based decision support system had been proposed in [11] for fertilizer recommendation by evaluating primary nutrients $(\mathrm{N}, \mathrm{P}, \mathrm{K})$ for the wheat crops. In [12], Extreme Learning Machine (ELM) had been employed to evaluate soil fertility using the soil attributes of $\mathrm{K}, \mathrm{P}, \mathrm{OC}, \mathrm{pH}$, and $\mathrm{B}$. Shinde et al. [13] utilized data mining concepts for the evaluation of fertilizer requirements. An integrated AHP and GIS approach based spatial decision support system framework was proposed by Shokati et al. [14] to evaluate Damask rose's fertilizer requirement. A fuzzy-logic-based 
decision support system was presented in [15] to assess the cotton plants' fertilizer requirements.

There are various studies in which GIS and MCDA model had been integrated to address the issues of multiple fields such as - land suitability analysis, agriculture, forestry, urban planning, transportation, geology, and ecology, etc. [9], [14], [15], [16], [17], [18].

In this study, an integrated web GIS-MCDA framework has been developed for fertility assessment of soil using open source software and tools, i.e., PostgreSQL, PostGIS, Geoserver, Apache Tomcat server, Open layers, GeoExt, Javascript, and CGI script.

Our key contributions are as follows-

1. Developing a web GIS based MCSDSS framework for the assessment of soil's fertility of the farmland using specific soil attributes.

2. Identification of the specific soil attributes and their importance in the soil's fertility assessment process.

3. Evaluation of the developed framework using various measures.

The rest of the paper is organized as follows. Section 2 presents the material and methods employed for developing the proposed framework. Section 3 offers a description of evaluation measures. Section 4 presents the results of experimentation and discussions. Finally, section 5 concludes the study.

\section{MATERIAL AND METHODS}

This section provides the details of the study area, the dataset used, MCDA models, and the architecture of the proposed MCSDSS framework.

\subsection{Study area}

The study was conducted at Abhanpur block located in Raipur district, Chhattisgarh, India (Figure 1). The study area lies between $20^{\circ} 56^{\prime} 25^{\prime \prime} \mathrm{N}$ to $21^{\circ} 10^{\prime} 27^{\prime \prime} \mathrm{N}$ latitude and $81^{\circ} 34^{\prime}$ $37^{\prime \prime} \mathrm{E}$ to $81^{\circ} 59^{\prime} 5^{\prime \prime} \mathrm{E}$ longitude, and at an elevation ranging from $256 \mathrm{~m}$ to $305 \mathrm{~m}$ above sea level. The total surface area is about $614.68 \mathrm{~km}^{2}$, and the climate is characterized by tropical wet and dry. The annual mean rainfall is about 51 inches, and the temperature ranges from $48^{\circ} \mathrm{C}$ (summer) to $5^{\circ} \mathrm{C}$ (winter). Agriculture is the primary occupation of the study area.

\subsection{Dataset}

The dataset was collected from the National Bureau of Soil Survey and Land Use Planning Department, Nagpur, (at the scale of 1:50,000) and standardized for integration into GIS and analysis using MCDA models. Table 1 describes the soil attributes used for the study, and Figure 2 shows their spatial distribution. The agriculture expert assigned the fertility levels of low, moderate, and high to the farmlands for evaluation purposes.

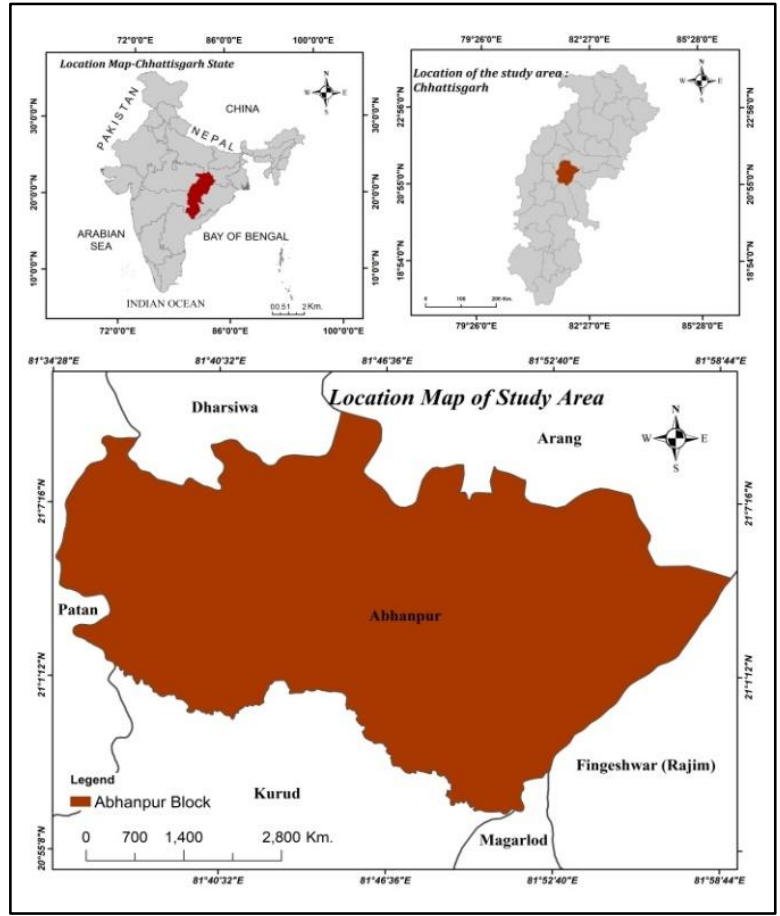

Fig 1: Location map of the study area.

Table1: Soil attributes used for the study and their descriptions [19].

\begin{tabular}{|c|c|c|}
\hline $\begin{array}{l}\text { S. } \\
\text { No. }\end{array}$ & $\begin{array}{c}\text { Soil } \\
\text { Attribute }\end{array}$ & Description \\
\hline 1 & $\begin{array}{l}\text { Nitrogen } \\
\text { (N) }\end{array}$ & $\begin{array}{l}\text { Nitrogen is a part of the } \\
\text { chlorophyll molecule. It is a vital } \\
\text { component for plant growth. Its } \\
\text { deficiency causes reduced plant } \\
\text { growth and yield, delay in fruiting, } \\
\text { yellow leaves, etc. }\end{array}$ \\
\hline 2 & $\begin{array}{l}\text { Phosphorus } \\
\text { (P) }\end{array}$ & $\begin{array}{l}\text { Phosphorus is also an essential } \\
\text { component for plant growth, } \\
\text { responsible for developing new } \\
\text { tissues, and it involves an energy } \\
\text { transfer process. Its deficiency } \\
\text { causes reduced plant growth, } \\
\text { purple stem, and poor flowering, } \\
\text { etc. }\end{array}$ \\
\hline 3 & $\begin{array}{l}\text { Potassium } \\
(\mathrm{K})\end{array}$ & $\begin{array}{l}\text { Potassium plays a vital role in the } \\
\text { metabolism activation process and } \\
\text { improves the plant's immunity. It is } \\
\text { responsible for the transfer of } \\
\text { water, nutrients, and carbohydrates } \\
\text { over the plant's tissues. }\end{array}$ \\
\hline 4 & $\begin{array}{l}\text { Potential of } \\
\text { Hydrogen } \\
(\mathrm{pH})\end{array}$ & $\begin{array}{l}\text { It shows the concentration of the } \\
\text { hydrogen ion. Its value ranges from } \\
0 \text { to } 14 \text {. Value } 7 \text { indicates a neutral } \\
\text { point, values above } 7 \text { are alkaline, } \\
\text { and values below } 7 \text { are acidic. }\end{array}$ \\
\hline 5 & $\begin{array}{l}\text { Cation } \\
\text { Exchange } \\
\text { Capacity } \\
\text { (CEC) }\end{array}$ & $\begin{array}{l}\text { It is an essential component that } \\
\text { shows the soil's capacity to supply } \\
\text { three vital nutrients to the plant, } \\
\text { i.e., Calcium, Magnesium, and } \\
\text { Potassium. }\end{array}$ \\
\hline 6 & $\begin{array}{l}\text { Magnesium } \\
(\mathrm{Mg})\end{array}$ & $\begin{array}{l}\text { It is also a vital component of } \\
\text { chlorophyll molecules. It makes } \\
\text { leaves appear green in color. }\end{array}$ \\
\hline
\end{tabular}




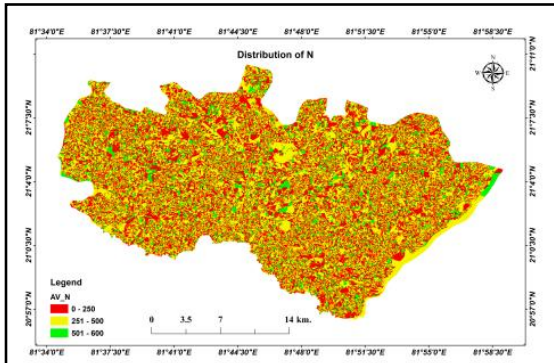

(a)

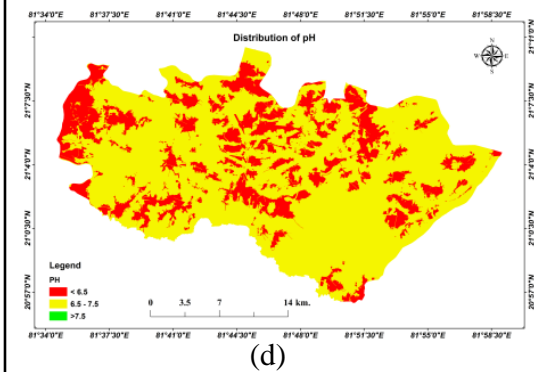

(d)

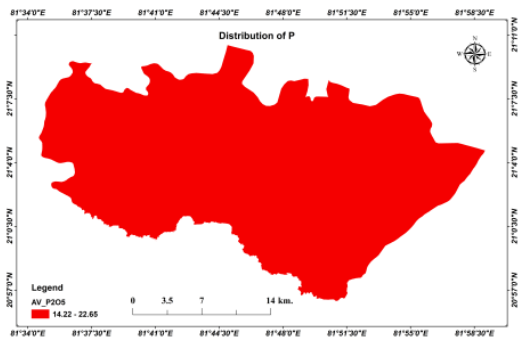

(b)

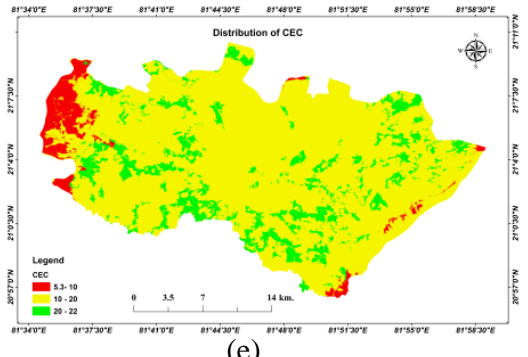

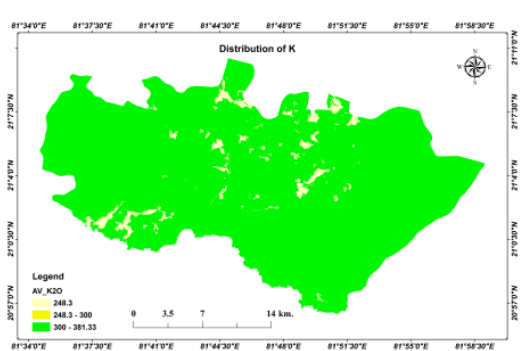

(c)

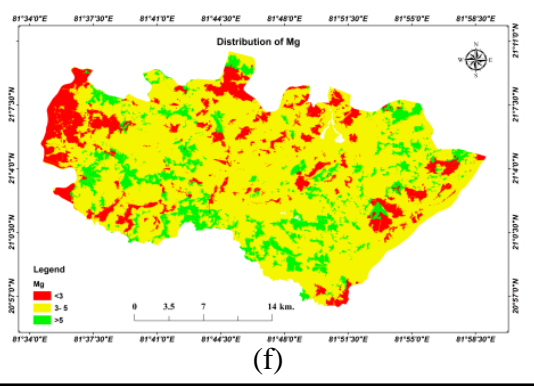

Fig 2: Spatial distribution of the soil attributes a. Nitrogen b. Phosphorus c. Potassium d. Potential of Hydrogen e. Cation Exchange Capacity f. Magnesium

\subsection{Multi-Criteria Decision Analysis (MCDA)}

Multi-Criteria Decision Analysis (MCDA) is a structured and systematic decision-making framework used to address complex and uncertain problems characterized by multiple conflicting criteria with a differing degree of importance [20]. The fertility of the soil relies on numerous soil attributes with a differing degree of importance. Hence, in this study, WSM, WPM, and WSPAS MCDA models are employed to evaluate soil fertility levels.

\subsubsection{Weighted Sum Model (WSM)}

Weighted Sum Model (WSM), also known as simple additive weighting (SAW) or weighted linear combination (WLC), is the simplest and most often used MCDA model for singledimensional problems [21] [22] [23]. In this model, an alternative's preference score is computed by the summation of the product of criteria value with their weights or importance as in eq. (1).

$S_{i}=\sum_{j=1}^{n} V_{i j} * W_{j}$

Where, $S_{i}=$ score of $i^{\text {th }}$ alternative, $V_{i j}=$ criteria value of $i^{\text {th }}$ alternative with respect to $j^{\text {th }}$ criteria, $W_{j}=$ weight or importance of $j^{\text {th }}$ criteria, assuming that there are $m$ alternatives and $n$ criteria or attributes. In this study, $\mathrm{m}=140082$ (number of soil records) and $\mathrm{n}=6$ (number of criteria) have been taken.

The decision-making process of the model comprises the following steps.

Step 1: Determine the weights of identified important criteria so that $\sum_{j=1}^{n} w_{j}=1$

Step 2: Represent the alternatives in the form of a decision matrix $\left[X_{i j}\right]$, where $X_{i j}$ denotes the numeric value of $i^{\text {th }}$ alternative with respect to $j^{\text {th }}$ criteria.

Step 3: Normalize the decision matrix using the eq. (2) (beneficial criteria) or eq. (3) (non-beneficial criteria).
$N_{i j}=\underbrace{\frac{X_{i j}}{\max }\left(X_{i j}\right)}_{i}$

$N_{i j}=\frac{\underbrace{\min }_{i}\left(X_{i j}\right)}{X_{i j}}$

Step 4: Compute the weighted normalized decision matrix as in eq. (4).

$V_{i j}=N_{i j} * w_{j}$

Step 5: Compute the preference score of alternatives using eq. (5).

$S_{i}=\sum_{j=1}^{n} V_{i j}$

Step 6: Rank the alternatives according to their preference scores $S_{i}$ from highest to lowest.

\subsubsection{Weighted Product Model (WPM)}

It is similar to WSM. The main difference is that the multiplication operation is performed instead of summation to get the preference scores as in eq. (6) [23].

$S_{i}=\prod_{j=1}^{n} N_{i j}{ }^{W_{j}}$

The decision-making process comprises the following steps.

Step 1: Similar to the WSM model.

Step 2: Similar to the WSM model.

Step 3: Similar to the WSM model.

Step 4: Compute the weighted normalized decision matrix as in eq. (7).

$V_{i j}=N_{i j} W_{j}$

Step 5: Compute the preference score of alternatives using eq. (8).

$S_{i}=\prod_{j=1}^{n} V_{i j}$

Step 6: Rank the alternatives according to their preference scores $S_{i}$ from highest to lowest. 


\subsubsection{Weighted Aggregated Sum Product Assessment (WASPAS)}

This model was introduced by Saparauskas et al. [24]. It is a composite form of the WSM model and WPM model. If $S_{i}{ }^{1}$ and $S_{i}{ }^{2}$ are the preference scores of $i^{\text {th }}$ alternative with respect to WSM and WPM respectively, then the weighed aggregated scores of the alternatives are computed as in eq. (9).

$S_{i}=\lambda S_{i}^{1}+(1-\lambda) S_{i}^{2}$

Where $\lambda$ rages from 0 and 1 . In this study, we have taken $\lambda=$ 0.5. Ranking of the alternatives are performed based on their preference scores $S_{i}$ from highest to lowest.

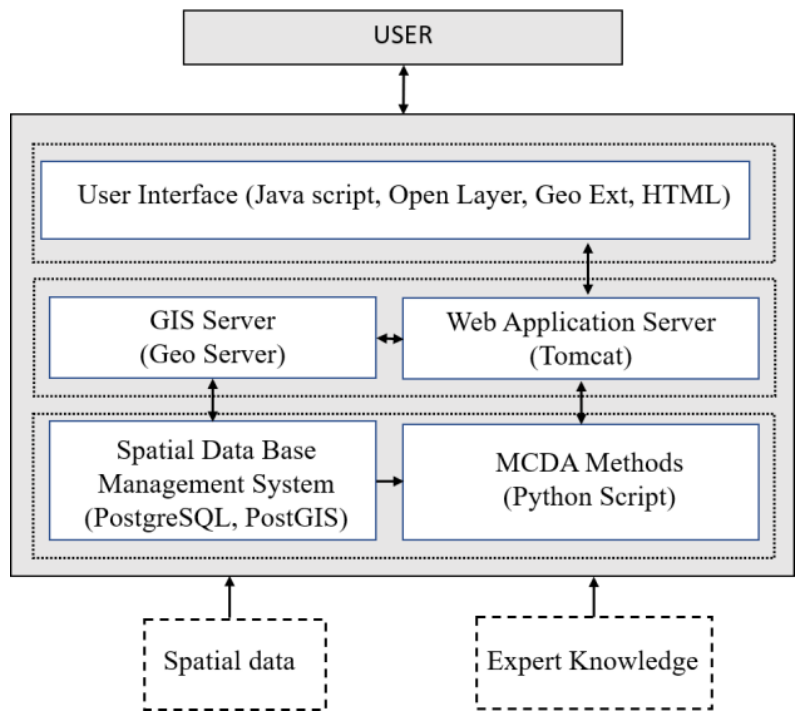

Fig 3: The architecture of the proposed framework.

\subsection{The architecture of the proposed framework}

The basic architecture of the proposed web-based spatial decision support system is shown in Figure 3. The spatial soil dataset has been imported into the database management system, i.e., PostgreSQL using PostGIS importer. Web-server (Apache Tomcat) serves the queries received from the user. GIS server (GeoServer) enables us to visualize and interact with the spatial database. OpenLayer and GeoExt API have been used for handling user-related queries on the published soil map. For the development of the MCDA models, macros are written in CGI scripts.

\section{EVALUATION MEASURES}

It is essential for any study to compare the real-world situation with the predicted situation using evaluation measures. In this study, accuracy, recall, precision, and F1-score are employed to evaluate MCDA models' performance, which are structured according to the confusion matrix of Table 2 . The rows of the matrix denote actual soil categories, and columns denote the predicted categories of soil. Correct predictions are true positive (TP) and true negative (TN). On the other hand, false predictions are false positive (FP) and false negative (FN).

$$
\begin{aligned}
& \text { 1. Accuracy- Accuracy }=\frac{T P+T N}{T P+T N+F P+F N} \\
& \text { 2. Precision- Precision }=\frac{T P}{(T P+F P)} \\
& \text { 3. Recall- Recall }=\frac{T P}{(T P+F N)}
\end{aligned}
$$

4. F1-score- F1score $=\frac{2 *(\text { Precision } * \text { Recall })}{(\text { Precision }+ \text { Recall })}$

Table 2: Confusion matrix.

\begin{tabular}{|c|c|c|c|}
\cline { 3 - 4 } \multicolumn{2}{c|}{} & \multicolumn{2}{c|}{$\begin{array}{c}\text { Predicted soil } \\
\text { category }\end{array}$} \\
\cline { 3 - 4 } \multicolumn{2}{c|}{} & Positive & Negative \\
\hline $\begin{array}{c}\text { Actual } \\
\text { soil } \\
\text { category }\end{array}$ & Positive & TP & FN \\
\cline { 2 - 4 } & Negative & FP & TN \\
\hline
\end{tabular}

\section{RESULT AND DISCUSSION}

In this study, the soil dataset of the Abhanpur block of Chhattisgarh state (India), comprised of 140082 field records, has been used for the experimentation. Initially, an agriculture expert's opinion has been taken to select soil attributes and their importance in the soil fertility assessment process. As suggested by him, six soil attributes, i.e., N, P, K, pH, CEC, and $\mathrm{Mg}$ with the weightage $0.25,0.25,0.25,0.15,0.05,0.05$, respectively, are used as input parameters for MCDA models. Based on computed soil fertility index (FI) or performance scores with MCDA models, soil fertility level is classified into three categories of Low fertile $(\mathrm{FI}<0.7)$, Moderate Fertile $(0.7<=\mathrm{FI}<=0.82)$, and High fertile $(\mathrm{FI}>0.82)$. In contrast, the fertilizer requirements are High fertilizer $(\mathrm{FI}<0.7)$, Moderate Fertilizer $(0.7<=\mathrm{FI}<=0.82)$, and Low fertilizer $(\mathrm{FI}>0.82)$.

The evaluation measures computed for the MCDA models are given in Table 3. It is evident that the WPM outperformed among all MCDA models with an accuracy of $82.9 \%$. The WASPAS model's performance is also comparable to WPM.

It can be observed from Figure 4 that $251.58 \mathrm{sq}$. km. of the study area falls under the "Low" fertile area, 263.7 sq. km. falls under the "Moderate" fertile area, and 99.4 sq. km. falls under the "High" fertile area (i.e., Ground Truth or GT). Also, it is apparent from Figure 4 that WASPAS is very close to the real conditions or GT in terms of predicting "Low" (240.6 sq. km.) and "Moderate" (243.7 sq. km.) fertile areas, while WPM is close in predicting "High" (119.8 sq. km.) fertile areas.

The experimentation results demonstrate that the WPM MCDA model with the combination of 6 selected soil attributes can achieve higher classification accuracy for the soil fertility classification. Also, the set of soil attribute weights are compatible for the soil fertility assessment process.

It has been observed that all the models employed in the study follow simple computational steps. They all are based on manipulating the decision matrix, so there is no limitation on the number of alternatives and criteria. The WPM is capable of providing more accurate classification results than WASPAS and WSM. Also, WPM and WASPAS models are close to the real situation in terms of area (sq. km.) prediction.

\section{CONCLUSION}

The present study aimed to evaluate the fertilizer requirements of the farmland based on the soil's fertility status with the combined approach of GIS-MCDA in the direction of smart agriculture system development. The spatial and multi-criteria aspects of the agriculture sector have led us to develop a spatial decision support system. The study suggests that the integrated approach of GIS and the MCDA model is an effective and user-friendly framework for suggesting the fertility status of a spatial location. The proposed framework 
will be useful for the development of appropriate strategies and options for soil fertility assessment. Overall, the proposed approach is valuable in bringing the agriculture sector and Information Technology domain into a single framework.

Table 3: Results of MCDA models

\begin{tabular}{|c|c|c|c|c|}
\hline $\begin{array}{c}\text { MCDA } \\
\text { method }\end{array}$ & $\begin{array}{c}\text { Accuracy } \\
(\boldsymbol{\%})\end{array}$ & $\begin{array}{c}\text { Precision } \\
(\boldsymbol{\%})\end{array}$ & $\begin{array}{c}\text { Recall } \\
(\boldsymbol{\%})\end{array}$ & $\begin{array}{c}\text { F1- } \\
\text { score } \\
(\boldsymbol{\%})\end{array}$ \\
\hline WSM & 0.705 & 0.711 & 0.738 & 0.708 \\
\hline WPM & 0.829 & 0.804 & 0.833 & 0.814 \\
\hline WASPAS & 0.812 & 0.788 & 0.824 & 0.799 \\
\hline
\end{tabular}

\section{Area Predicted by the MCDA models}

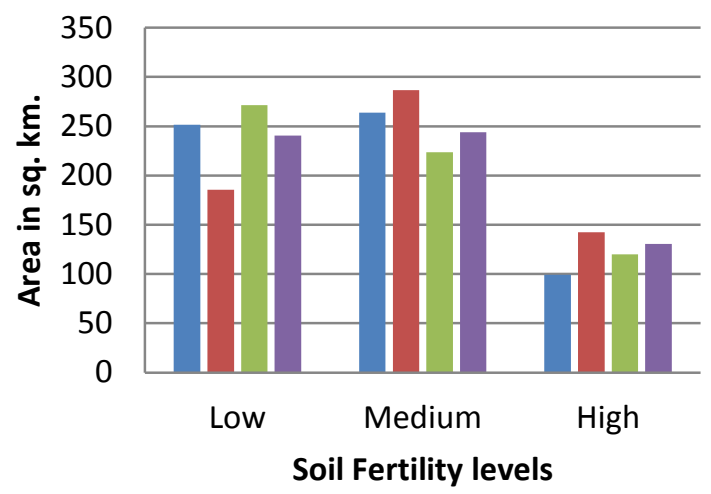

$\square$ GT WSM WPM $\square$ WASPAS

Fig 4: Area in sq. km. as predicted by MCDA methods under three categories of soil fertility levels.

\section{ACKNOWLEDGMENTS}

We would like to acknowledge the National Bureau of Soil Survey and Land Use Planning Department, Nagpur, for providing the dataset.

\section{REFERENCES}

[1] Tilman, D., Cassman, K.G., Matson, P.A., Naylor, R. and Polasky, S. 2002. Agricultural sustainability and intensive production practices. Nature, 418(6898), pp.671-677.

[2] Jallah, J.K., Mulbah, C.K., Kiazolu, J.S., Frank, K. and Morris, M.Z. 1991. Efficient fertilizer use for increased crop production: The Liberia experience. In Alleviating Soil Fertility Constraints to Increased Crop Production in West Africa (pp. 155-164). Springer, Dordrecht.

[3] Simonne, E.H., Gazula, A., Ozores-Hampton, M., DeValerio, J. and Hochmuth, R.C. 2017. Localized application of fertilizers in vegetable crop production. In Advances in Research on Fertilization Management of Vegetable Crops (pp. 149-181). Springer, Cham.

[4] Fao, F.A.O.S.T.A.T. 2008. Food and agriculture organisation of the United Nations.

[5] Patnaik, P. 2017. Handbook of environmental analysis: chemical pollutants in air, water, soil, and solid wastes. Crc Press.
[6] Savci, S. 2012. Investigation of effect of chemical fertilizers on environment. Apcbee Procedia, 1, pp.287292.

[7] Mir, S.A. and Quadri, S.M.K. 2009. Decision support systems: concepts, progress and issues-A review. In Climate change, intercropping, pest control and beneficial microorganisms (pp. 373-399). Springer, Dordrecht.

[8] Mendas, A. and Delali, A. 2012. Integration of MultiCriteria Decision Analysis in GIS to develop land suitability for agriculture: Application to durum wheat cultivation in the region of Mleta in Algeria. Computers and Electronics in Agriculture, 83, pp.117-126.

[9] Malczewski, J. 2006. GIS- based multi-criteria decision analysis: a survey of the literature. International journal of geographical information science, 20(7), pp.703-726.

[10] Lavanya, G., Rani, C. and Ganeshkumar, P. 2020. An automated low cost IoT based Fertilizer Intimation System for smart agriculture. Sustainable Computing: Informatics and Systems, 28, p.100300.

[11] Ashraf, A., Akram, M. and Sarwar, M. 2014. Fuzzy decision support system for fertilizer. Neural Computing and Applications, 25(6), pp.1495-1505.

[12] Suchithra, M.S. and Pai, M.L. 2020. Improving the prediction accuracy of soil nutrient classification by optimizing extreme learning machine parameters. Information Processing in Agriculture, 7(1), pp.72-82.

[13] Shinde, K., Andrei, J. and Oke, A. 2015. Web Based Recommendation System for Farmers. International Journal on Recent and Innovation Trends in Computing and Communication, 3(3), pp.41-52.

[14] Seyedmohammadi, J., Sarmadian, F., Jafarzadeh, A.A. and McDowell, R.W. 2019. Development of a model using matter element, AHP and GIS techniques to assess the suitability of land for agriculture. Geoderma, 352, pp.80-95.

[15] Gilliams, S., Raymaekers, D., Muys, B. and Van Orshoven, J. 2005. Comparing multiple criteria decision methods to extend a geographical information system on afforestation. Computers and electronics in agriculture, 49(1), pp.142-158.

[16] Jamil, M., Ahmed, R. and Sajjad, H. 2018. Land suitability assessment for sugarcane cultivation in Bijnor district, India using geographic information system and fuzzy analytical hierarchy process. GeoJournal, 83(3), pp.595-611.

[17] Silva, S., Alçada-Almeida, L. and Dias, L.C. 2014. Development of a Web-based Multi-criteria Spatial Decision Support System for the assessment of environmental sustainability of dairy farms. Computers and Electronics in Agriculture, 108, pp.46-57.

[18] Özkan, B., Dengiz, O. and Turan, İ.D. 2019. Site suitability assessment and mapping for rice cultivation using multi-criteria decision analysis based on fuzzyAHP and TOPSIS approaches under semihumid ecological condition in delta plain. Paddy and Water Environment, 17(4), pp.665-676.

[19] Barker, A.V. and Pilbeam, D.J. eds. 2015. Handbook of plant nutrition. CRC press. 
[20] Mardani, A., Jusoh, A., Nor, K., Khalifah, Z., Zakwan, N. and Valipour, A. 2015. Multiple criteria decisionmaking techniques and their applications-a review of the literature from 2000 to 2014. Economic ResearchEkonomska Istraživanja, 28(1), pp.516-571.

[21] Triantaphyllou, E. 2000. Multi-criteria decision making methods. In Multi-criteria decision making methods: A comparative study (pp. 5-21). Springer, Boston, MA.

[22] Fishburn, P.C. 1967. Letter to the editor-additive utilities with incomplete product sets: application to priorities and assignments. Operations Research, 15(3), pp.537-542.

[23] Triantaphyllou, E. and Mann, S.H. 1989. An examination of the effectiveness of multi-dimensional decisionmaking methods: a decision-making paradox. Decision Support Systems, 5(3), pp.303-312.

[24] Šaparauskas, J., Kazimieras Zavadskas, E. and Turskis, Z. 2011. Selection of facade's alternatives of commercial and public buildings based on multiple criteria. International Journal of Strategic Property Management, 15(2), pp.189-203. 